\title{
Green Building Occupant Satisfaction: Evidence from the Australian Higher Education Sector
}

\author{
Maryam Khoshbakht ${ }^{1}$, Zhonghua Gou ${ }^{1}$ (D) , Xiaohuan Xie ${ }^{2,3, *}$, Baojie $\mathrm{He}^{4}$ and Amos Darko ${ }^{5}$ (10) \\ 1 School of Engineering and Built Environment, Griffith University, Gold Coast, QLD 4215, Australia; \\ m.kh@griffith.edu.au (M.K.); z.gou@griffith.edu.au or gouzhonghua@gmail.com (Z.G.) \\ 2 School of Architecture and Urban Planning, Shenzhen University, Shenzhen 518060, China \\ 3 Shenzhen Key Laboratory of Built Environment Optimization, Shenzhen University, Shenzhen 518060, China \\ 4 Faculty of Built Environment, University of New South Wales, Sydney NSW 2052, Australia; \\ baojie.he@unsw.edu.au \\ 5 Department of Building and Real Estate, The Hong Kong Polytechnic University, Hong Kong, China; \\ amos.darko@connect.polyu.hk \\ * Correspondence: xiexiaohuan@szu.edu.cn; Tel.: +86-18664331877
}

Received: 30 June 2018; Accepted: 8 August 2018; Published: 15 August 2018

\begin{abstract}
Universities spend billions of dollars on green buildings as a sustainability commitment. This research investigates occupant satisfaction with indoor environmental quality (IEQ), building design (BD), and facilities management (FM) in five highly ranked green higher educational buildings in the subtropical climate of Australia, in comparison to nine non-green counterparts. The results disclose that the green building users were more consistently satisfied than the non-green building users with BD\&FM elements, such as design, needs from facilities, building image, cleaning, the availability of meeting rooms, and storage. On the other hand, the study revealed weaknesses of green buildings in IEQ, such as noise, ventilation, and artificial lighting. The individual environmental control positively correlated with satisfaction in non-green buildings, but did not significantly affect satisfaction in green buildings. This study also identified the influences of non-environmental factors on occupant satisfaction, such as gender, age, sitting close to a window, hours spent in the building and in the workstation, and the number of people sharing office space. The research provides evidence and guidance for investing in, designing, and managing green educational facilities.
\end{abstract}

Keywords: green building; occupant satisfaction; indoor environment quality; building design; facilities management; higher education

\section{Introduction}

Green buildings are designed to represent an architecture that is environmentally responsible and resource efficient through the buildings' whole life cycle [1]. Green rating tools have been initiated to accelerate sustainable transformation towards more energy- and resource-efficient, and healthy and productive buildings [2]. Nevertheless, the role of green rating tools in improving indoor environmental quality and occupant experience in green buildings is uncertain [3]. A contradictory body of knowledge regarding the impact of green buildings on employees and occupant satisfaction has been reflected in earlier studies as a result of varying research methods and measures [4]. Occupant experience and environmental satisfaction in offices are influenced by several environmental conditions such as thermal, visual, acoustics, and air quality, as well as workplace features such as privacy, furniture, needs, cleanliness, and environmental controls [5,6].

Most green building occupant satisfaction studies come from the U.S. and the U.K., and there are emerging studies from Asia, especially China [7]. The number of green building occupant 
satisfaction studies from Australia is small. Australia launched the Green Star programme in 2003; until December 2017, 1462 projects had been certified. There is an urgent call for examination of these certified buildings. To meet this call, this research presents an occupant satisfaction study on Green Star buildings in Australia. Particularly, this study focuses on the higher educational sector. Many universities are investing billions of dollars into constructing green buildings showcasing their sustainability commitment [8]. These green buildings are used for science laboratories to incubate innovative green technologies; they are also used for offices to facilitate academic and research activities. The study aims to provide evidence from users' experience to examine these green education facilities.

\section{Literature Review}

Many studies can be found on the relationship between green certifications and indoor environmental quality (IEQ) investigating occupant satisfaction with factors such as thermal comfort, air quality, lighting, and noise. There are also papers considering other parameters in relation to building design and facilities management (BD\&FM) such as privacy, environmental control, cleanliness, operation and maintenance, design, aesthetics, image, needs, ease of interaction with co-workers, furniture, health, and productivity.

The available survey data from the Centre of the Built Environment (CBE) at the University of Berkley in California have been used in several studies analyzing LEED (Leadership in Energy and Environmental Design) buildings [5,9-11], resulting in a large amount of data being used in these papers. In terms of thermal comfort satisfaction, most studies detected a higher performance in LEED buildings compared with in conventional buildings. However, several studies indicated no significant difference in the thermal performance of LEED and non-LEED buildings [5]. Indoor air quality (IAQ) was also perceived more satisfactory in LEED buildings when compared with non-green buildings [9-13]. The lighting and noise performance of LEED buildings showed significant inconsistency in the literature. In terms of lighting performance in LEED buildings, most papers detected no significant differences $[5,9,11]$. However, two studies indicated a higher satisfaction score [12,13], and two papers [10,14] reported a lower satisfaction score in LEED buildings. As reflected in the literature, LEED buildings are the least successful in terms of noise performance as the majority of papers either reported no significant differences $[5,9,11]$, or lower satisfaction scores $[10,12,14]$ in LEED buildings in comparison with in non-LEED buildings. One paper [15], however, reported a higher satisfaction score in overall noise performance of LEED buildings, and another study [15] indicated that noise from HVAC (Heating, ventilation, and air conditioning) was perceived to be more satisfactory in LEED buildings. Abbaszade et al. [9] emphasized the necessity for improvements in lighting controls and sound privacy through the accommodation of innovative strategies in open-plan offices in both LEED and non-LEED buildings. In terms of BD\&FM, most papers [10,13-15] reflected a more satisfactory performance in LEED buildings.

Studies focused on BREEAM (Building Research Establishment Environmental Assessment Method) (the most common certification tool in Europe) reflected an inconsistent result in analyzing various IEQ and BD\&FM parameters. In terms of overall thermal performance, two studies $[16,17]$ reported lower satisfaction scores, while another paper [3] showed satisfaction scores were comparable in BREEAM and non-BREEAM buildings with no significant differences. All papers studying IAQ [3,18] reported lower satisfactory results in BREEAM buildings compared with in their conventional counterparts. Lighting performance in BREEAM buildings, however, was slightly better than other IEQ parameters, as two papers $[16,17]$ detected higher and two papers $[3,18]$ reported no significant differences in satisfaction in the green and non-green groups. No significant differences in the noise performance of BREEAM and non-BREEAM buildings were perceived according to the literature [3,16-18]. In one study [18], noise from outside was scored lower in BREEAM buildings than in non-green buildings. One study [3] reported that the satisfaction results in BREEAM and non-BREEAM buildings were not significantly different, particularly in regard to sound privacy, the ease of interaction with colleagues, cleanliness, and workplace satisfaction. The study also reported a lower satisfaction level in visual privacy in BREEAM-certified buildings compared with in conventional buildings [3]. 
Indoor environmental controls in BREEAM buildings scored no significant differences in the two compared groups [16]. In one study [16], operation and maintenance achieved higher satisfaction in BREEAM buildings when compared with their conventional counterparts.

Some studies have investigated Green Star buildings in Australia, and have particular relevance for our study. Some papers reported no significant differences in the performance of Green Star buildings compared with conventional buildings, particularly in overall perceived thermal comfort [19,20], lighting [19], ventilation [19], and noise [19] performance. In another Australian-based study [21], a wide spectrum of Green Star building performances was evident, with some high-profile green buildings outperforming their conventional counterparts, but some green buildings underperformed when compared with conventional buildings. The same study [18] reported less satisfactory performances for Green Star buildings by showing green buildings underperforming their conventional counterparts in terms of thermal comfort satisfaction and perceived productivity. The study [21] also demonstrated that Green Star buildings generally outperformed the conventional buildings in terms of perceived health, building image, and addressing occupant needs.

\section{Research Hypotheses}

The literature review discloses the common satisfaction aspects investigated in previous studies, mainly covering indoor environment quality (IEQ), building design (BD), and facilities management (FM). The hypothesis of green buildings outperforming non-green buildings turned out to be inconsistent, especially in terms of IEQ factors, while less inconsistent on BD\&FM. The previous studies discussed many environmental factors (such as environmental control and ventilation) and non-environmental factors (such as gender, age, and occupancy conditions) which influenced the occupant satisfaction outcome. For the present study, four hypotheses are to be tested:

Hypothesis 1. Compared with non-green building users, green building users are more consistently satisfied with BDEFM.

Hypothesis 2. Compared with non-green building users, green building users are less consistently satisfied with IEQ.

Hypothesis 3. Environmental factors (environmental controls and ventilation types) significantly influence occupant satisfaction in green and non-green buildings.

Hypothesis 4. Non-environmental factors (age, gender, being close to a window, hours spent in the building and in their workstations, and number of people sharing office space) significantly influence occupant satisfaction in green and non-green buildings.

\section{Methodology}

\subsection{Building Selection}

The sample for this study was selected from three major cities in Australia: Brisbane, Sydney, and the Gold Coast. Based on Koppen's climate classification, the climate conditions in these three cities are categorized as subtropical, with hot and humid summers and moderately dry, warm winters [22]. The seasonal temperature variation is relatively small in all cities. The average seasonal temperature range is $10{ }^{\circ} \mathrm{C}$ to $30{ }^{\circ} \mathrm{C}$ for Brisbane, $13{ }^{\circ} \mathrm{C}$ to $23{ }^{\circ} \mathrm{C}$ for Sydney, and $12{ }^{\circ} \mathrm{C}$ to $29{ }^{\circ} \mathrm{C}$ for the Gold Coast [23]. Due to higher average temperatures in summer, Brisbane and the Gold Coast experience slightly warmer summers compared with Sydney. Average relative humidity is estimated as $50 \%$ for Brisbane, $65 \%$ for Sydney, and $60 \%$ for the Gold Coast [23].

The criteria for selecting buildings were as follows: located in an Australian subtropical climate; a higher education building; Green Star certified if rated as green; accommodating office 
spaces for academic and administrative staff; and finally, occupied for more than twelve months. The investigation to find appropriate case studies involved visiting each building in order to obtain approvals from building managers. Finally, five green and nine non-green buildings were selected for the survey (Figure 1).

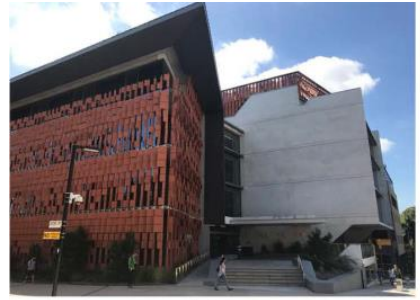

(a)

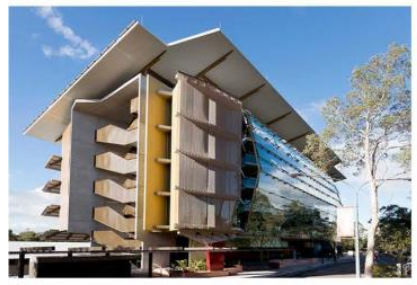

(d)

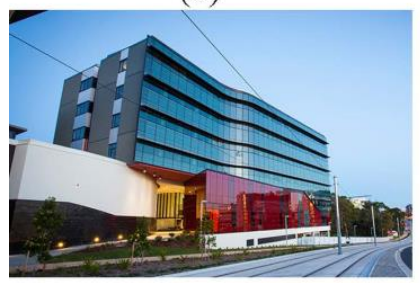

(g)

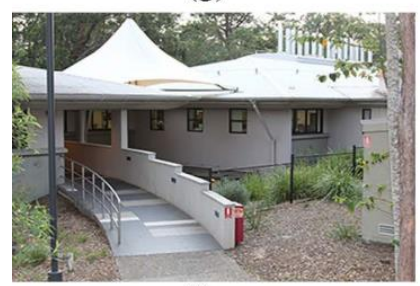

(j)

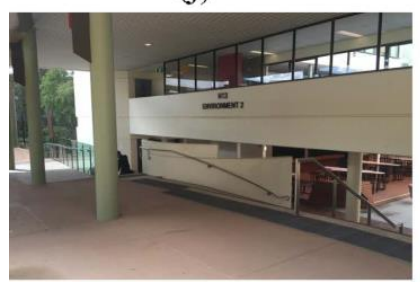

(m)

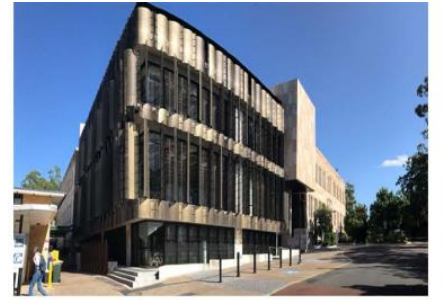

(b)

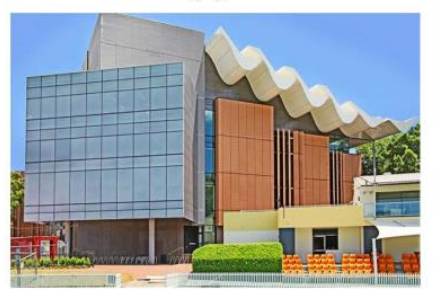

(e)

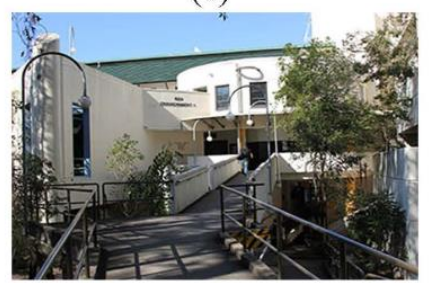

(h)

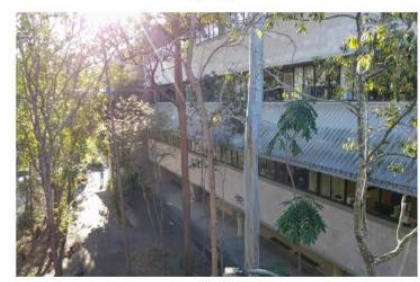

(k)

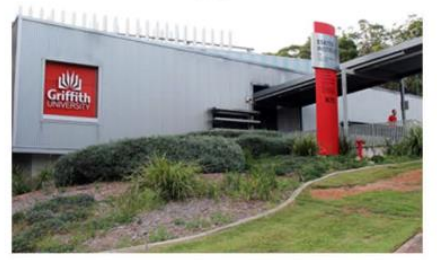

(n)

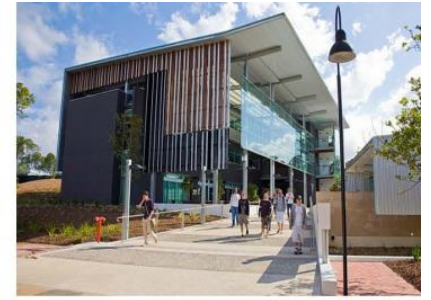

(c)

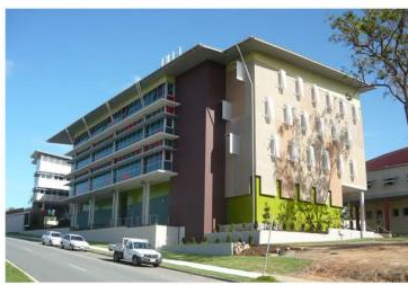

(f)

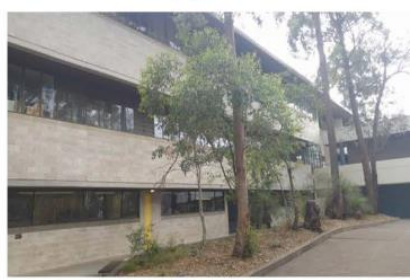

(i)

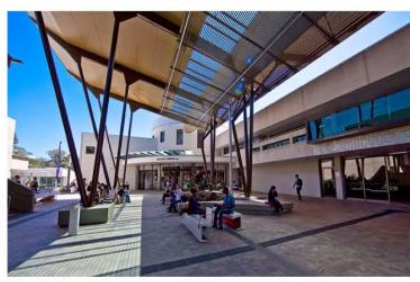

(1)

Figure 1. Surveyed green and non-green buildings: (a) Advanced Engineering Building (Green building no. 1); (b) Global Change Institute (Green building no. 2); (c) Mirvac School of Sustainable Development (Green building no. 3); (d) Sir Samuel Griffith Centre (Green building no. 4); (e) TYREE Energy Technologies Building (Green building no. 5); (f) Science, Engineering and Architecture Building (Non-green building no. 1); (g) Business School (Non-green building no. 2); (h) Griffith Environment Building 1 (Non-green building no. 3); (i) Griffith Science Building 1 (Non-green building no. 4); (j) Griffith Institute for Drug Discovery 1 (Non-green building no. 5); (k) Griffith Science Building 2 (Non-green building no. 6); (l) Willett Centre (Non-green building no. 7); (m) Griffith Environment Building 2 (Non-green building no. 8); (n) Griffith Institute for Drug Discovery 2 (Non-green building no. 9). 
A paper questionnaire survey seeking occupant perceptions of a range of parameters was distributed throughout these buildings. Survey collections were undertaken one week after distribution. To increase participation and ensure a healthy response rate, paper surveys were selected as an alternative solution to web-based questionnaires. The aim was to obtain at least a $75 \%$ response rate in all buildings. The data collection of surveys started in March 2016 and was finalized in September 2017. The survey consisted of a two-page paper questionnaire developed by Building Use Studies (BUS) [24]. The BUS methodology survey was considered relevant, having been effectively applied in various research works worldwide [25-27]. The dataset sample in this study reflects 631 responses from the 5 Green-Star-certified and 9 non-green buildings.

\subsection{Surveys (BUS Method)}

The questionnaire consists of two major sections: background information and satisfaction scores. Background information concerns participant basic information regarding age, gender, the time they started working in the building, the location of participant offices in terms of distance to a window, office layout, and the duration of stay in the building, further including duration at desks, and duration behind visual display units. The second part of the survey consists of 48 questions requiring scores on a 7-point scale for different building parameters. The 7-point scale response has been designed to cover a wide range of occupant experiences and satisfaction levels [16]. A value rate in the bottom three points of the 7-point scale is considered to be dissatisfaction, and the top three rates are considered to be satisfaction [24].

The 45 occupant satisfaction questions include IEQ parameters and BD\&FM factors [16] (see Table 1). IEQ parameters include questions regarding temperature in summer and winter, noise, and lighting. The BD\&FM parameters obtain opinions regarding building image, design, space, safety, cleaning, the availability of meeting rooms and storage, occupant health, productivity and behavior, and response to problems. A more detailed description and the full text of the BUS surveys are included in Baird and Thompson [28].

Table 1. Survey questionnaire structure and format detail.

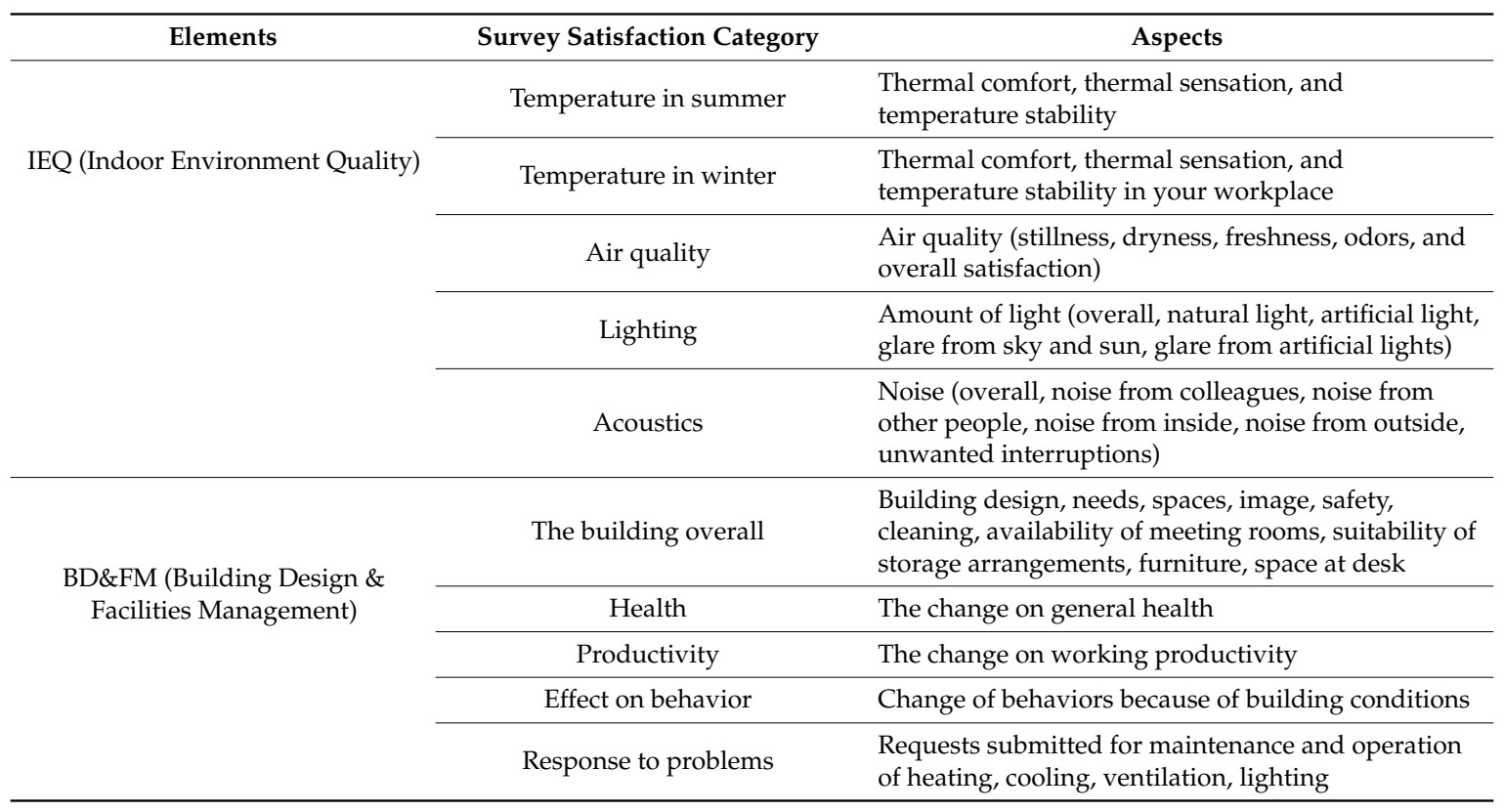

\subsection{Dataset Descriptions}

Tables 2 and 3 summarize the sample characteristics of green and conventional building sets, respectively. All buildings in both groups are higher education institutional buildings and 
accommodate spaces for academic offices and other higher education activities, such as research and administration. They are equipped with various types of ventilation systems (air-conditioned, zoned mixed-mode ventilation, and changeover mixed-mode ventilation) and environmental controls (automated and manual).

Both comparison sets have a large variation in terms of building sizes (from 15 to 400 occupants). To show a consistency in building sizes in the comparison groups, we used building size benchmarking suggested by the U.S. Energy Information Administration [1]. Based on gross floor area (GFA), buildings in both comparing sets were divided into three groups of small, medium, and large. Small includes buildings with GFA equal to or lower than $4645 \mathrm{~m}^{2}$; medium includes buildings with GFA between $4645 \mathrm{~m}^{2}$ and 18,580 $\mathrm{m}^{2}$; and large includes buildings with GFA higher than $18,580 \mathrm{~m}^{2}$. As presented in Tables 4 and 5 , both building sets include at least one building from each building size group. In terms of urban location, both comparing groups incorporate buildings in urban and suburban regions. The building age of both building groups was compatible as all buildings were either built or renovated after 2007. In terms of sample size, we had more buildings in the non-green group than in the green building set. However, the average number of responses per building was compatible in the two comparing sets. On average, we gathered 32.6 responses per building in the green building set and 52 responses per building in the non-green building set (Table 4).

The distribution of individual occupant responses in the two building sets in terms of occupant characteristics, spatial layout, workspace features, and working activities is presented in Table 5 . In both building sets, the majority of users were included in the age group of over 30 years old. The number of males and females in green and non-green buildings was almost equally distributed. In both building sets, the majority of occupants ( $37 \%$ in green and $29 \%$ in non-green) indicated occupying a workspace shared with more than 8 people. Private offices occupied by only one person were the second most common in both groups ( $32 \%$ in green and $28 \%$ in non-green). Sharing with one person was the least common in both sets ( $2 \%$ in green and $10 \%$ in non-green), yet it was much less common in green buildings compared with in the non-green group. Surprisingly, sitting next to no windows was slightly more common in green buildings, whereas in the non-green set, the distribution of occupants sitting next to a window $(49 \%)$, and not sitting next to a window (51\%) was almost equal. The majority of participants (79\% in green and $81 \%$ in non-green) had worked in the buildings for more than a year in both building groups. In terms of work-related activities, the relative majority of respondents self-declared their job type as research in both groups ( $73 \%$ in green and $30 \%$ in non-green). 
Table 2. Summary of the features of the green building sets.

\begin{tabular}{|c|c|c|c|c|c|c|c|c|c|c|c|}
\hline No. & Certificate & Type & University & Urban Setting & Location & Built/Reno & $\begin{array}{c}\text { GFA (Gross } \\
\text { Floor Area) }\left(\mathrm{m}^{2}\right)\end{array}$ & Measured Dates & Sample & Size & Ventilation \\
\hline 1 & $\begin{array}{c}5 \text { Star Green Design \& } \\
\text { As Built }\end{array}$ & Research & University of Queensland & Urban & Brisbane & 2014 & 18,000 & 2017 & 53 & Large & $\mathrm{MM}^{*}$ \\
\hline 2 & $\begin{array}{c}6 \text { Star Green Design \& } \\
\text { As Built }\end{array}$ & Academic & University of Queensland & Urban & Brisbane & 2013 & 3865 & 2017 & 11 & Small & MM \\
\hline 3 & $\begin{array}{c}6 \text { Star Green Design \& } \\
\text { As Built }\end{array}$ & Academic & Bond University & Suburban & Gold Coast & 2007 & & 2017 & 15 & Small & MM \\
\hline 4 & $\begin{array}{c}6 \text { Star Green Design \& } \\
\text { As Built }\end{array}$ & Academic & Griffith University & Suburban & Brisbane & 2014 & 7299 & 2016 & 32 & Medium & $\mathrm{AC} * *$ \\
\hline 5 & $\begin{array}{c}6 \text { Star Green Design \& } \\
\text { As Built }\end{array}$ & Research & University of New South Wales & Urban & Sydney & 2012 & 15,000 & 2014 & 52 & Large & $\mathrm{AC}$ \\
\hline
\end{tabular}

${ }^{*}$ MM represents mixed-mode buildings, which have a changeover combination of natural ventilation and an active cooling system. ${ }^{* *} \mathrm{AC}$ represents air conditioning.

Table 3. Summary of the features of the conventional building sets.

\begin{tabular}{|c|c|c|c|c|c|c|c|c|c|c|}
\hline No & Type & University & Setting & Location & Built/Reno & GFA $\left(m^{2}\right)$ & Measured Dates & Sample & Size & Ventilation \\
\hline 1 & Academic & Griffith University & Urban & Gold Coast & 2010 & 7266 & 2017 & 39 & Medium & $A C^{* *}$ \\
\hline 2 & Academic & Griffith University & Urban & Gold Coast & 2014 & 7498 & 2017 & 47 & Medium & $\mathrm{AC}$ \\
\hline 3 & Academic & Griffith University & Suburban & Brisbane & 2012 & 7815 & 2017 & 46 & Medium & $\mathrm{AC}$ \\
\hline 4 & Academic & Griffith University & Suburban & Brisbane & 2011 & 3308 & 2017 & 25 & Small & $\mathrm{AC}$ \\
\hline 5 & Research & Griffith University & Suburban & Brisbane & 2007 & 2327 & 2017 & 20 & Small & $\mathrm{AC}$ \\
\hline 6 & Academic & Griffith University & Suburban & Brisbane & 2010 & 10,322 & 2017 & 46 & Large & MM* \\
\hline 7 & Library & Griffith University & Suburban & Brisbane & 2016 & 18,227 & 2017 & 151 & Large & $\mathrm{AC}$ \\
\hline 8 & Academic & Griffith University & Suburban & Brisbane & 2009 & 7,507 & 2017 & 49 & Medium & $\mathrm{AC}$ \\
\hline 9 & Research & Griffith University & Suburban & Brisbane & 2008 & 4,469 & 2017 & 45 & Small & $\mathrm{AC}$ \\
\hline
\end{tabular}

${ }^{*}$ MM represents mixed-mode buildings, which have a changeover combination of natural ventilation and an active cooling system. ${ }^{* *} \mathrm{AC}$ represents air conditioning. 
Table 4. Dataset descriptions of the selected case studies.

\begin{tabular}{ccccc}
\hline Dataset & Green Star & Non-Green Star & Total & $\begin{array}{c}\text { Number of Responses } \\
\text { per Building (Average) }\end{array}$ \\
\hline Number of buildings & 5 & 9 & 14 & 32.6 \\
\hline $\begin{array}{c}\text { Number of } \\
\text { occupant responses }\end{array}$ & 163 & 468 & 631 & 52 \\
\hline
\end{tabular}

Table 5. The distribution of individual occupant responses in the two building sets in terms of occupant characteristics, spatial layout, workspaces features, and working activities.

\begin{tabular}{|c|c|c|c|}
\hline \multirow[b]{2}{*}{ Non-Environmental Factors } & \multirow{2}{*}{ Groups } & \multicolumn{2}{|c|}{ Individual Occupant Responses } \\
\hline & & $\begin{array}{c}\text { Green Star } \\
\text { Number (Percentage) }\end{array}$ & $\begin{array}{c}\text { Non-Green Star } \\
\text { Number (Percentage) }\end{array}$ \\
\hline \multirow{2}{*}{ Age } & Age $<30$ & $57(34 \%)$ & $96(20 \%)$ \\
\hline & Age $>30$ & $106(65 \%)$ & $369(79 \%)$ \\
\hline \multirow{2}{*}{ Sex } & Male & $95(59 \%)$ & $225(49 \%)$ \\
\hline & Female & $66(41 \%)$ & $238(51 \%)$ \\
\hline \multirow{5}{*}{ Spatial layout } & Nominated only by 1 & $52(32 \%)$ & $132(28 \%)$ \\
\hline & Shared office with 1 other & $3(2 \%)$ & $45(10 \%)$ \\
\hline & Shared office with $2-4$ others & $29(18 \%)$ & $78(17 \%)$ \\
\hline & Shared office with $5-8$ others & $18(11 \%)$ & $73(16 \%)$ \\
\hline & Shared office with more than 8 & $61(37 \%)$ & $137(29 \%)$ \\
\hline \multirow{2}{*}{ Workplace features } & Sit next to a window & $72(44 \%)$ & $228(49 \%)$ \\
\hline & No window nearby & $91(56 \%)$ & $236(51 \%)$ \\
\hline \multirow{2}{*}{ Building occupation } & $\begin{array}{l}\text { Worked in the building less } \\
\text { than a year }\end{array}$ & $32(29 \%)$ & $90(19 \%)$ \\
\hline & $\begin{array}{l}\text { Worked in the building more } \\
\text { than a year }\end{array}$ & $79(71 \%)$ & $374(81 \%)$ \\
\hline \multirow{5}{*}{ Working activity type } & Research & $114(73 \%)$ & $123(30 \%)$ \\
\hline & Academic & $23(15 \%)$ & $60(15 \%)$ \\
\hline & Information services & $1(1 \%)$ & $107(26 \%)$ \\
\hline & Administration & $10(6 \%)$ & $69(17 \%)$ \\
\hline & Management & $9(6 \%)$ & $43(11 \%)$ \\
\hline
\end{tabular}

\subsection{Statistical Technique}

STATA 13.0 software was used to conduct the statistical analysis for this research. The mean (M) satisfaction scores for the two comparing building sets regarding 45 different indoor environmental quality parameters were determined. The theoretical framework utilized in this study is adapted from the study by Lin and Liu [29]. In this research, the standardized size of the mean difference (effect size index) between the two building sets was calculated using Spearman Rank Correlation (Rho). The effect size is an index for calculating the magnitude of effect or association between two or more predictor variables [30]. For the purpose of benchmarking effect sizes, Cohen [31] defined an effect size smaller than 0.20 as negligible, equal to 0.20 as small, equal to 0.50 as moderate, and equal to or larger than 0.80 as large effect size. For the purpose of correlation study, pairwise correlations were conducted to determine correlation coefficient and statistical significance. In addition, the statistical significance of mean differences or null hypothesis was also calculated. The null hypothesis examines the significance of statistical differences based on the Bonferroni method [32]. The correlation is statistically significant, and the null hypothesis is rejected, if the $p$-value is less than $5 \%(p<0.05)$ [32].

In order to increase the significance of the results, individual user scores were utilized instead of average scores from each building. Accordingly, 631 datapoints were considered instead of 15 which was the number of buildings in the dataset. This helps to consider the effect of other influencing factors such as workstation features or space layout in the analysis. In fact, using an average score from each building as a statistical unit would artificially increase variance and, thus, would reduce correlation coefficients, which would lead to the loss of information [5]. With the method of utilizing individual 
participant responses as a statistical unit, for example, a building with only 11 responses would not be statistically equal to a building with 151 participants. This paper focuses on user satisfaction in green buildings rather than individual green building performances.

\section{Results}

\subsection{IEQ Satisfaction}

Figure 2 compares green and non-green buildings in terms of IEQ satisfaction. It shows similarities and differences between the two groups. The inferential $t$-test revealed statistically significant differences between the performance of Green Star and conventional buildings in terms of most IEQ parameters, particularly in overall thermal comfort ( $p$-value $=0.004$ in winter; $p$-value $=0.001$ in summer), overall air satisfaction ( $p$-value $=0.000$ in winter; $p$-value $=0.000$ in summer), and overall noise satisfaction ( $p$-value $=0.006$ ). Green buildings outperformed conventional buildings in thermal $(\Delta \mathrm{M}=0.34$ in winter; $\Delta \mathrm{M}=0.54)$ and IAQ parameters $(\Delta \mathrm{M}=0.52$ in winter; $\Delta \mathrm{M}=0.68$ in summer). In terms of noise, conventional buildings outperformed Green Star buildings $(\Delta \mathrm{M}=-0.45)$. No significant differences in lighting scores $(p$-value $=0.301)$ were detected in the two comparison groups. The IAQ and thermal performance of green buildings scored slightly higher in summer $(\Delta \mathrm{M}=0.68$ in IAQ; $\Delta \mathrm{M}=0.54$ in thermal) than in winter ( $\Delta \mathrm{M}=0.52$ in IAQ; $\Delta \mathrm{M}=0.34$ in thermal).

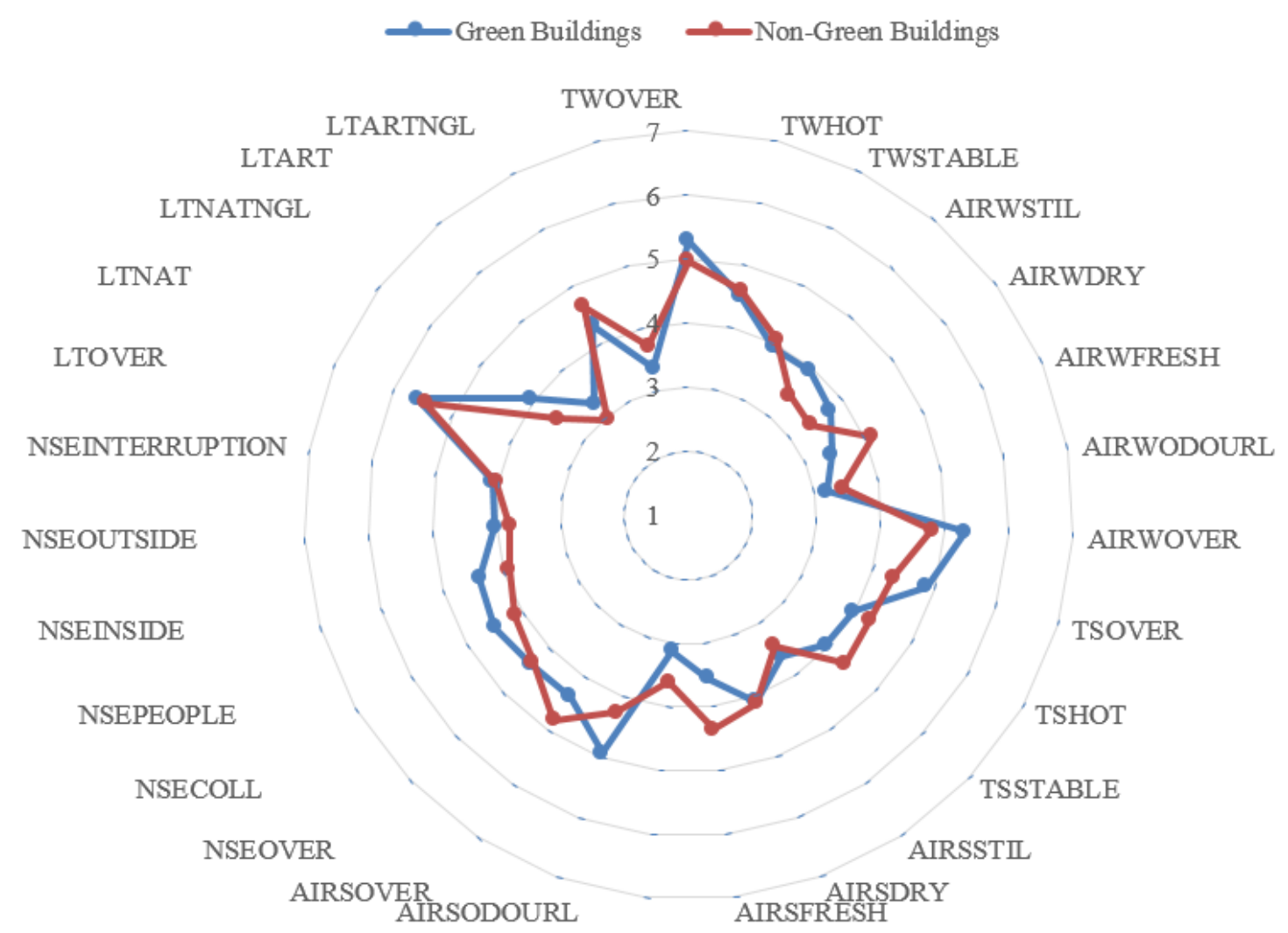

Figure 2. Comparison analysis of IEQ parameters in green and non-green building sets.

A more detailed analysis of the 27 IEQ parameters showing the mean values, standard deviations, the difference in standard errors, the difference in mean values, effect sizes, and the statistical significances ( $p$-value) of satisfaction scores in Green Star and conventional buildings is presented in Table 6. Numbers in bold italics show statistically significant $t$-tests with $p$-values less than 0.05 , and substantive effect sizes with values more than 0.20 . 
Table 6. Mean satisfaction scores in IEQ parameters.

\begin{tabular}{|c|c|c|c|c|c|c|c|c|}
\hline \multirow{2}{*}{ IEQ Parameters } & \multicolumn{2}{|c|}{ Green Buildings } & \multicolumn{2}{|c|}{ Non-Green Buildings } & \multirow{2}{*}{$\begin{array}{l}\text { Diff } \\
\text { SE }\end{array}$} & \multirow{2}{*}{$\Delta \mathbf{M}$} & \multirow{2}{*}{ Rho } & \multirow{2}{*}{$p$-Value } \\
\hline & $\mathbf{M}$ & SD & M & SD & & & & \\
\hline $\begin{array}{l}\text { TWOVER (Overall } \\
\text { comfort in winter) }\end{array}$ & 5.29 & 2.64 & 4.97 & 2.19 & 0.153 & 0.34 & 0.14 & $0.004^{* *}$ \\
\hline $\begin{array}{l}\text { TWHOT (Temperature } \\
\text { in winter) }\end{array}$ & 4.52 & 2.18 & 4.61 & 1.92 & 0.109 & -0.09 & -0.05 & 0.225 \\
\hline $\begin{array}{c}\text { TWSTABLE } \\
\text { (Temperature stability } \\
\text { in winter) }\end{array}$ & 3.95 & 2.30 & 4.07 & 2.19 & 0.172 & -0.12 & -0.05 & 0.150 \\
\hline $\begin{array}{c}\text { AIRWSTIL (Air } \\
\text { movement in winter) }\end{array}$ & 3.95 & 2.05 & 3.45 & 1.78 & 0.138 & 0.50 & $0.27 *$ & $0.001 * *$ \\
\hline $\begin{array}{l}\text { AIRWDRY (Air dryness } \\
\text { in winter) }\end{array}$ & 3.76 & 1.85 & 3.38 & 1.70 & 0.122 & 0.39 & $0.22 *$ & $0.001^{* *}$ \\
\hline $\begin{array}{l}\text { AIRWFRESH (Air } \\
\text { freshness in winter) }\end{array}$ & 3.43 & 1.99 & 4.13 & 1.96 & 0.145 & -0.71 & $-0.36^{*}$ & $0.000^{* *}$ \\
\hline $\begin{array}{l}\text { AIRWODOURL (Air } \\
\text { odors in winter) }\end{array}$ & 3.19 & 1.85 & 3.45 & 1.86 & 0.153 & -0.26 & -0.14 & 0.085 \\
\hline $\begin{array}{l}\text { AIRWOVER (Air } \\
\text { overall in winter) }\end{array}$ & 5.33 & 2.01 & 4.81 & 2.06 & 0.143 & 0.52 & $0.26^{*}$ & $0.000 * *$ \\
\hline $\begin{array}{l}\text { TSOVER (Overall } \\
\text { comfort in summer) }\end{array}$ & 4.88 & 1.90 & 4.34 & 1.99 & 0.169 & 0.54 & $0.28 *$ & $0.001 * *$ \\
\hline $\begin{array}{l}\text { TSHOT (Temperature } \\
\text { in summer) }\end{array}$ & 3.97 & 1.54 & 4.26 & 1.84 & 0.143 & -0.29 & -0.16 & $0.047^{* *}$ \\
\hline $\begin{array}{c}\text { TSSTABLE } \\
\text { (Temperature stability } \\
\text { in summer) }\end{array}$ & 3.95 & 1.91 & 4.36 & 2.08 & 0.172 & -0.41 & -0.20 & $0.018^{* *}$ \\
\hline $\begin{array}{c}\text { AIRSSTIL (Air } \\
\text { movement in summer) }\end{array}$ & 3.62 & 1.46 & 3.43 & 1.67 & 0.136 & 0.20 & 0.12 & 0.144 \\
\hline $\begin{array}{l}\text { AIRSDRY (Air dryness } \\
\text { in summer) }\end{array}$ & 4.09 & 1.48 & 4.11 & 1.83 & 0.140 & -0.02 & -0.01 & 0.904 \\
\hline $\begin{array}{c}\text { AIRSFRESH (Air } \\
\text { freshness in summer) }\end{array}$ & 3.55 & 1.74 & 4.36 & 1.88 & 0.150 & -0.81 & $-0.44^{*}$ & $0.000^{* *}$ \\
\hline $\begin{array}{l}\text { AIRSODOURL (Air } \\
\text { odors in summer) }\end{array}$ & 3.13 & 1.78 & 3.62 & 1.84 & 0.157 & -0.48 & $-0.26 *$ & $0.002^{* *}$ \\
\hline $\begin{array}{l}\text { AIRSOVER (Air overall } \\
\text { in summer) }\end{array}$ & 4.94 & 1.87 & 4.27 & 1.93 & 0.159 & 0.68 & $0.35 *$ & $0.000^{* *}$ \\
\hline $\begin{array}{c}\text { NSEOVER } \\
\text { (Noise overall) } \\
\end{array}$ & 4.37 & 2.07 & 4.82 & 2.01 & 0.162 & -0.45 & $-0.22 *$ & $0.006^{* *}$ \\
\hline $\begin{array}{l}\text { NSECOLL (Noise } \\
\text { from colleagues) }\end{array}$ & 4.38 & 1.69 & 4.33 & 1.64 & 0.128 & 0.05 & 0.03 & 0.697 \\
\hline $\begin{array}{l}\text { NSEPEOPLE (Noise } \\
\text { from other people) }\end{array}$ & 4.49 & 1.74 & 4.12 & 1.62 & 0.130 & 0.38 & $0.23 *$ & $0.004^{* *}$ \\
\hline $\begin{array}{l}\text { NSEINSIDE (Noise } \\
\text { from inside) }\end{array}$ & 4.40 & 1.78 & 3.92 & 1.58 & 0.132 & 0.49 & $0.30 *$ & $0.000 * *$ \\
\hline $\begin{array}{l}\text { NSEOUTSIDE (Noise } \\
\text { from outside) }\end{array}$ & 4.02 & 1.84 & 3.78 & 1.65 & 0.141 & 0.24 & 0.14 & 0.089 \\
\hline $\begin{array}{l}\text { NSEINTERRUPTION } \\
\text { (unwanted noise } \\
\text { interruptions) }\end{array}$ & 4.10 & 1.90 & 4.04 & 1.91 & 0.157 & 0.06 & 0.03 & 0.691 \\
\hline $\begin{array}{c}\text { LTOVER } \\
\text { (Overall lighting) }\end{array}$ & 5.60 & 1.87 & 5.46 & 1.90 & 0.137 & 0.14 & 0.07 & 0.301 \\
\hline $\begin{array}{c}\text { LTNAT } \\
\text { (Natural lighting) }\end{array}$ & 4.07 & 1.69 & 3.53 & 1.81 & 0.150 & 0.55 & $0.31 *$ & $0.000^{* *}$ \\
\hline $\begin{array}{l}\text { LTNATNGL (Glare } \\
\text { from natural lighting) }\end{array}$ & 3.28 & 1.90 & 2.96 & 1.96 & 0.174 & 0.32 & 0.16 & 0.067 \\
\hline $\begin{array}{c}\text { LTART } \\
\text { (Artificial lighting) }\end{array}$ & 4.32 & 1.37 & 4.65 & 1.56 & 0.100 & -0.33 & $-0.22 *$ & $0.001 * *$ \\
\hline $\begin{array}{l}\text { LTARTNGL (Glare from } \\
\text { artificial lighting) }\end{array}$ & 3.36 & 1.73 & 3.72 & 1.78 & 0.147 & -0.36 & -0.20 & $0.015^{* *}$ \\
\hline
\end{tabular}

\footnotetext{
${ }^{*}$ Rho more than $0.20 ;{ }^{* *} p$-value less than 0.05 .
} 
Green buildings achieved significantly higher satisfaction in some IEQ parameters including overall air in summer $(\mathrm{Rho}=0.35)$, overall comfort in summer $(\mathrm{Rho}=0.28)$, air dryness in winter $($ Rho $=0.22)$, overall air in winter $($ Rho $=0.26)$, air movement in winter $($ Rho $=0.35)$, natural light $($ Rho $=0.31)$, and inside noise $($ Rho $=0.30)$.

However, the green building set gained lower satisfaction scores in a number of IEQ parameters, such as air freshness in both summer $(\mathrm{Rho}=-0.44)$ and winter $(\mathrm{Rho}=-0.36)$, air odors in summer $(\mathrm{Rho}=-0.26)$, artificial lighting $(\mathrm{Rho}=-0.22)$, and overall noise $(\mathrm{Rho}=-0.22)$. The maximum differences in the mean values of satisfaction scores belonged to air freshness in summer with a negative difference in mean values of -0.81 (the mean score of green buildings minus the mean score of conventional buildings), and air overall in summer with a positive difference in mean values of 0.68 .

The inferential tests showed that users of Green Star and non-Green Star buildings had similar satisfaction scores, with $p$-value more than 0.05 in regard to some IEQ factors, such as temperature in winter $($ Rho $=-0.05)$, temperature stability in winter $(\mathrm{Rho}=-0.05)$, air odors in winter $(\mathrm{Rho}=-0.14)$, air movement in summer $(\mathrm{Rho}=0.12)$, air dryness in summer $(\mathrm{Rho}=-0.01)$, noise from colleagues $(\mathrm{Rho}=0.03)$, noise from outside (Rho $=0.14)$, unwanted interruptions $(\mathrm{Rho}=0.03)$, overall lighting $($ Rho $=0.07)$, and glare from natural lighting $($ Rho $=0.16)$.

In regard to IEQ parameters, the comparative analysis of satisfaction scores in green and conventional buildings detected a significant correlation between Green Star certifications and occupant satisfaction with workplace environments.

\subsection{BDEFM Satisfaction}

Figure 3 compares green and non-green buildings in terms of BD\&FM satisfaction. The mean satisfaction scores, standard deviations, the difference in standard errors, mean differences, effect sizes, and statistical significances of satisfaction scores regarding BD\&FM parameters are presented in Table 7. Figures in bold italics show statistically significant $t$-tests with $p$-values less than 0.05 , and substantive effect sizes with values more than 0.20 .

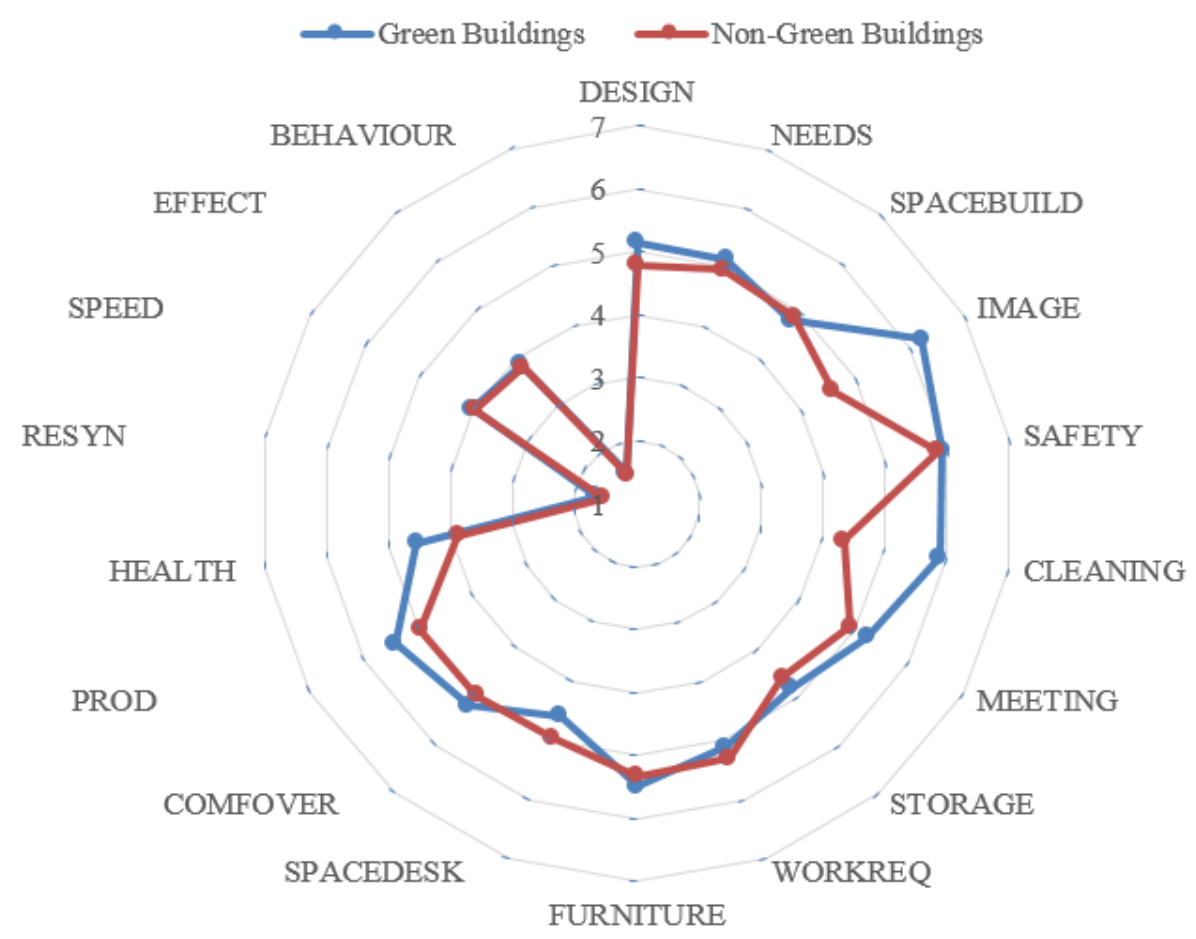

Figure 3. Comparison analysis of BD\&FM parameters in green and non-green building sets. 
Table 7. Mean satisfaction scores in BD\&FM parameters.

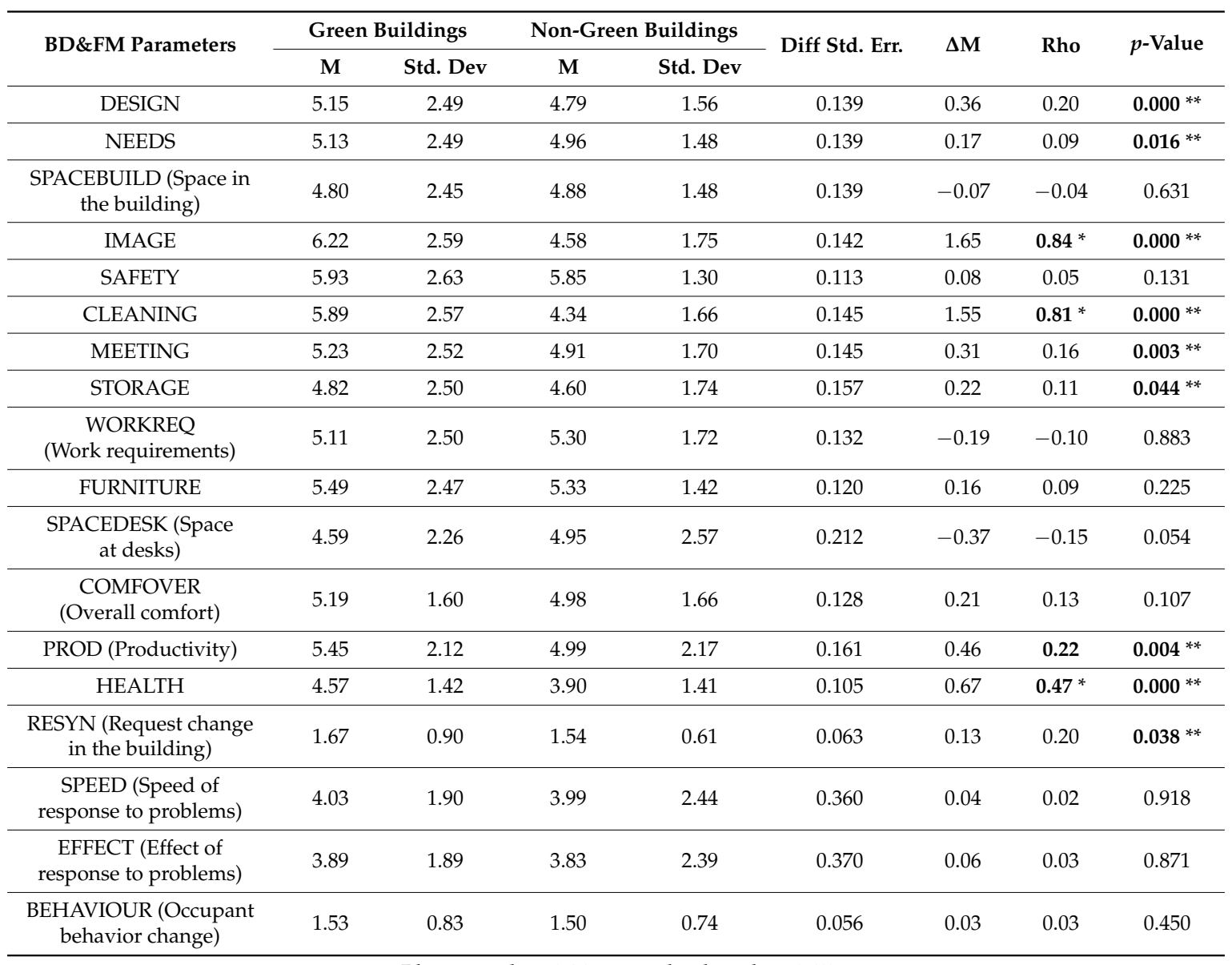

* Rho more than 0.20 ; ** $p$-value less than 0.05 .

In terms of BD\&FM factors, green buildings had significantly higher scores compared with non-green buildings, particularly in parameters such as image $($ Rho $=0.84)$ and cleaning $($ Rho $=0.81)$ with large effect sizes. With medium effect sizes, health $(\mathrm{Rho}=0.47)$ and productivity $(\mathrm{Rho}=0.22)$ scored higher in green buildings than in their conventional counterparts. The maximum difference in mean satisfaction scores regarding $B D \& F M$ parameters belonged to image ( $\triangle \mathrm{M}=1.65)$, and cleaning $(\Delta \mathrm{M}=1.55)$, both with positive values in mean differences (the mean score of green buildings minus the mean score of conventional buildings).

These results confirm that the green building users were more significantly satisfied than the non-green building users with most BD\&FM parameters, such as design, needs from facilities, building image, cleaning, the availability of meeting rooms, and storage. Perceived productivity and health was also reported higher in green buildings. Although occupant satisfaction was higher in green buildings, there were also more reported requests to fix problems in these buildings. This suggests that expectations and hopes of fixing problems are higher in green buildings than in conventional buildings. In green buildings, the most common complaint was noise, whereas in conventional buildings, more complaints about HVAC systems and temperatures were reported.

\subsection{The Influence of Environmental Factors}

To study the effect of indoor environmental factors on satisfaction scores, we conducted pairwise correlation studies to analyze the influence of individual controls and ventilation types. 


\subsubsection{Individual Control}

Although research has shown that personal control could significantly improve thermal comfort perceptions [33], the extent and comparison of the effect of personal controls in green and non-green buildings has not been studied. We analyzed the impact of perceived individual controls on satisfaction scores concerning five parameters including heating, cooling, ventilation, lighting, and noise. A pairwise correlation analysis showing the relationship between the following parameters is presented in Table 8: (1) heating control and thermal comfort in winter; (2) cooling control and thermal comfort in summer; (3) ventilation control and overall air quality satisfaction; (4) lighting control and overall lighting satisfaction; and (5) noise control and overall noise satisfaction.

Perceived controls in all five parameters were only significantly correlated with satisfaction scores in non-green buildings. Perceived heating control had a significant correlation ( $p$-value $=0.000$ ) with thermal comfort satisfaction in winter in non-green buildings, while no significant correlations were found between perceived heating control and winter thermal comfort in green building group. Cooling control was also strongly correlated with summer thermal comfort in the non-green building set $(p$-value $=0.000)$. Ventilation control significantly influenced overall air satisfaction $(p$-value $=0.018)$ in non-green buildings. Perceived control over lighting and noise in non-green buildings significantly correlated with satisfaction with overall lighting $(p$-value $=0.000)$ and acoustics ( $p$-value $=0.000$ ), whereas in green buildings, no significant correlations were detected between perceived control and satisfaction.

Table 8. The influence of perceived control on overall satisfaction scores.

\begin{tabular}{|c|c|c|c|c|c|}
\hline \multicolumn{2}{|c|}{ Perceived Personal Control-Perceived Satisfaction } & \multirow{2}{*}{$\begin{array}{c}\begin{array}{c}\text { Perceived } \\
\text { Control (M) }\end{array} \\
2.42\end{array}$} & \multirow{2}{*}{$\begin{array}{c}\begin{array}{c}\text { Satisfaction } \\
\text { (M) }\end{array} \\
4.96\end{array}$} & \multirow{2}{*}{$\begin{array}{c}\begin{array}{c}\text { Pairwise } \\
\text { Correlation }\end{array} \\
0.10\end{array}$} & \multirow{2}{*}{$\begin{array}{r}\boldsymbol{p} \text {-Value } \\
0.410\end{array}$} \\
\hline Heating - thermal comfort in winter & Green & & & & \\
\hline \multirow{2}{*}{ Cooling - thermal comfort in summer } & Green & 2.92 & 4.88 & 0.01 & 0.957 \\
\hline & Non-Green & 2.56 & 4.34 & 0.28 & $0.000 * *$ \\
\hline $\begin{array}{l}\text { Ventilation-average of overall air in } \\
\text { winter and summer }\end{array}$ & Non-Green & 2.29 & 4.55 & 0.11 & $0.018 * *$ \\
\hline \multirow{2}{*}{ Lighting—overall light } & Green & 2.78 & 5.60 & 0.16 & 0.184 \\
\hline & Non-Green & 3.59 & 5.46 & 0.17 & $0.000 * *$ \\
\hline Noise—overall noise & Green & 2.27 & 4.37 & 0.35 & 0.003 \\
\hline
\end{tabular}

\subsubsection{Ventilation}

This section reports the results of the influence of ventilation systems on occupant satisfaction in the green and non-green buildings. The difference in mean scores, effect sizes, and correlation significances is reported in Table 9. 
Table 9. Statistical analysis of ventilation influence on satisfaction scores in green and non-green buildings.

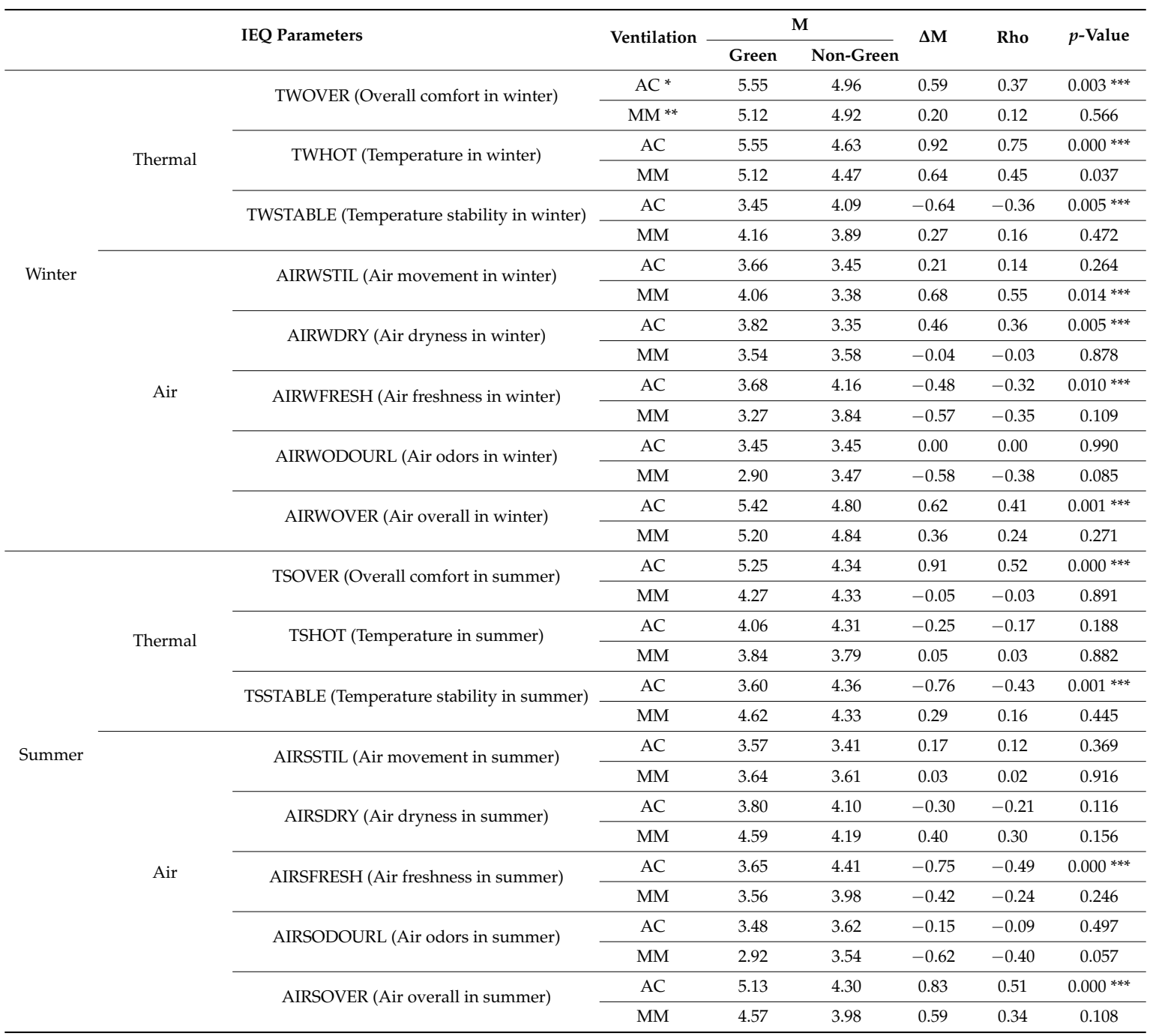

${ }^{*}$ AC represents air conditioning; ${ }^{* *}$ MM represent mixed-mode buildings, which have a changeover combination of natural ventilation and an active cooling system; ${ }^{* * *} p$-value less than 0.05 .

In thermal comfort, green buildings outperformed non-green air-conditioned (AC) buildings, while in mixed-mode (MM) buildings, no differences were detected in the thermal performance of the two comparison groups (green and non-green). In AC buildings, satisfaction with overall IAQ achieved higher scores in green buildings compared with in non-green buildings. Overall IAQ in MM buildings achieved comparable scores in green and non-green buildings. In terms of overall IAQ, the performance of green buildings in winter was perceived to be more satisfactory than in summer. In winter, indoor air was scored significantly more humid in AC green buildings and more stable in MM green buildings. In terms of air freshness, no significant differences in MM buildings were detected; nevertheless, non-green AC buildings achieved higher air freshness scores compared with green AC buildings.

This analysis showed that ventilation type affected satisfaction scores. The green buildings which had AC systems underperformed non-green buildings in terms of air freshness. Overall IAQ and overall thermal comfort in AC green buildings scored significantly higher when compared with non-green buildings, while no significant differences in overall scores were detected in MM buildings. 


\subsection{The Influence of Non-Environmental Factors}

To conduct a deeper analysis of the results, the influence of non-environmental factors such as age, gender, being close to a window, houses spent in the building and in the workstation, and number of people sharing office space was analyzed (Table 10). Statistical analysis of the mean comparison test was undertaken and effect sizes were calculated to explore whether non-environmental factors significantly affected satisfaction in green and non-green buildings.

The analysis of age groups (under 30, and 30 or above) revealed that for the group aged under 30 , no statistical difference in satisfaction scores was detected between green and non-green buildings $($ Rho $=-0.09)$. However, for the group aged 30 or above, the green building group achieved slightly higher satisfaction scores than the non-green building group $($ Rho $=0.28)$, suggesting that participant age might have an influence on satisfaction scores when comparing green and non-green buildings.

The statistical analysis of $t$-tests and the effect size of mean differences showed that gender had no significant influence on occupant satisfaction in Green Star and non-Green Star buildings. Negligible effect sizes were detected for both gender groups of male $($ Rho $=0.14$ and $p$-value $=0.256)$ and female $($ Rho $=0.18$ and $p$-value $=0.212$ ).

Table 10. The influence of non-environmental factors on overall comfort scores in green and non-green buildings.

\begin{tabular}{|c|c|c|c|c|c|c|}
\hline \multirow{2}{*}{ Non-Environmental Factors } & \multirow{2}{*}{ Type } & \multicolumn{2}{|c|}{$\mathbf{M}$} & \multirow{2}{*}{$\Delta \mathbf{M}$} & \multirow{2}{*}{ Rho } & \multirow{2}{*}{$p$-Value } \\
\hline & & Green & Non-Green & & & \\
\hline \multirow{2}{*}{ Age } & Under 30 & 4.88 & 5.00 & -0.13 & -0.09 & 0.612 \\
\hline & 30 or above & 5.35 & 4.97 & 0.38 & $0.28 *$ & $0.014^{* *}$ \\
\hline \multirow[b]{2}{*}{ Gender } & Male & 5.17 & 4.97 & 0.20 & 0.14 & 0.256 \\
\hline & Female & 5.23 & 4.99 & 0.24 & 0.18 & 0.212 \\
\hline \multirow{2}{*}{ Window } & Next to a window & 5.57 & 5.20 & 0.37 & $0.27 *$ & 0.051 \\
\hline & Not next to a window & 4.88 & 4.76 & 0.12 & 0.09 & 0.485 \\
\hline \multirow{2}{*}{$\begin{array}{l}\text { Started working in } \\
\text { the building }\end{array}$} & Less than a year & 5.58 & 5.48 & 0.10 & 0.08 & 0.698 \\
\hline & A year or more & 5.40 & 4.86 & 0.53 & $0.39 *$ & $0.002 * *$ \\
\hline \multirow{2}{*}{$\begin{array}{l}\text { Started working in } \\
\text { the workstation }\end{array}$} & Less than a year & 5.51 & 5.43 & 0.08 & 0.06 & 0.749 \\
\hline & A year or more & 5.42 & 4.87 & 0.55 & $0.40 *$ & $0.002 * *$ \\
\hline \multirow{5}{*}{ Office occupied by } & 1 only & 5.22 & 5.16 & 0.05 & 0.04 & 0.825 \\
\hline & 2 & 6.33 & 5.16 & 1.17 & $0.82 *$ & 0.177 \\
\hline & $3-5$ & 4.72 & 4.81 & -0.08 & -0.05 & 0.805 \\
\hline & $6-9$ & 4.44 & 4.75 & -0.31 & -0.21 * & 0.422 \\
\hline & More than 9 & 5.55 & 4.95 & 0.60 & 0.50 * & $0.002 * *$ \\
\hline
\end{tabular}

As participants were divided into two groups of sitting next to a window and not sitting next to a window, a small difference in the performance of green and non-green buildings was detected among participants in the group of sitting next to a window. A small effect size of mean differences between satisfaction scores in green and non-green buildings was observed in the group of sitting next to a window (Rho $=0.27$ and $p$-value $=0.051$ ). This suggests that the performance of green and non-green buildings was comparable among participants who sit far from a window, whereas green buildings achieved slightly higher scores from participants who sit next to a window.

To investigate the effect of the length of time occupants had been working in their current buildings and workstations, participants were grouped into two groups of less than a year, and a year or more. Participants who had been working in their buildings for a year or more reflected significant differences in satisfaction scores $(R h o=0.39$ and $p$-value $=0.002)$ between green and non-green buildings, whereas for those who had worked in their current building for less than a year, satisfaction scores were comparable in green and non-green buildings ( $\mathrm{Rho}=0.08$ and $p$-value $=0.698$ ). Similar results were found in regard to time spent in workstations, showing that participants who spent less than one year in their workstations reflected no significant differences between green and non-green buildings. High statistical differences between satisfaction scores in green and non-green 
buildings were marked by participants who spent a year or more in their workstations (Rho $=0.40$ and $p$-value $=0.002$ ). This finding showed that becoming used to changes and settling down in current workplaces affects occupant satisfaction and should be considered as an influential factor when comparing green and non-green buildings.

To explore the effect of office sharing on occupant satisfaction, the five office sharing conditions were as follows: Type 1, used only by one person; Type 2, used by two people; Type 3, used by three to five people; Type 4, used by six to nine people; and Type 5, used by more than nine people. An analysis of satisfaction scores in regard to office sharing with colleagues showed that participants in Type 5 delivered significantly higher scores in green buildings compared with in non-green buildings $($ Rho $=0.24$ and $p$-value $=0.000$ ). Although the effect sizes for Type 2 and Type 4 were more than 0.20 , the p-values showed that the results were not statistically significant. The effect size for Type 2 was large $($ Rho $=0.82)$, while the $p$-value was 0.177 . Similarly, for Type 4 , the effect size was just above 0.20 (Rho $=0.21$ ) showing a small effect size, but the $p$-value $(0.422)$ showed that the findings were not statistically significant. This can be explained by the sample size presented in Table 11 . The sample sizes, particularly in the green building groups for Type 2 (sample size $=3$ ) and Type 4 (sample size $=18$, were small.

Table 11. Occupant responses in the five types of office sharing.

\begin{tabular}{cccc}
\hline \multirow{2}{*}{ Type } & \multicolumn{3}{c}{ Number of Occupant Responses } \\
\cline { 2 - 4 } & Green Buildings & Non-Green Buildings & Total \\
\hline 1: 1 person & 45 & 132 & 177 \\
2: 2 persons & 3 & 45 & 48 \\
3: $3-5$ persons & 25 & 78 & 103 \\
4: 6-9 persons & 18 & 73 & 91 \\
5: more than 9 & 44 & 137 & 181 \\
persons & & & \\
\hline
\end{tabular}

These findings suggest that office sharing affects occupant experiences of buildings and thus influences satisfaction scores when comparing green and non-green buildings. Due to the sample sizing, the comparison of Types 2, 3, and 4 showed no statistically significant results. For Types 1 and 5, sample sizes were comparable, suggesting that green buildings were more favorable among participants in Type 5, whereas no significant differences between green and non-green buildings were reflected by occupants in Type 1.

\section{Discussion}

This study compared the occupant satisfaction and perceived indoor environmental conditions of Green Star higher education office buildings with their conventional counterparts regarding several IEQ and BD\&FM parameters. The two comparison building groups were consistent in terms of building size, year of construction or renovation, climate, function, cultural background, urban setting, and data collection period. This study showed that Green Star buildings were more successful in delivering satisfactory workplace environments regarding some IEQ and BD\&FM parameters, while some weaknesses were also detected that showed occupant dissatisfaction with Green Star buildings.

The results support Hypothesis 1 that on BD\&FM, Green Star buildings consistently showed a better performance compared with non-green buildings, particularly with overall building comfort, building design, needs, building image, cleaning, availability of meeting rooms, and storage space. Higher perceived health and productivity were found in Green Star buildings. This agrees with findings from previous studies [14,21,34].

The results also support Hypothesis 2 that on IEQ satisfaction, green buildings outperforming non-green buildings is inconclusive. It was shown that the occupants of Green Star buildings were more satisfied with thermal comfort and overall IAQ, a finding which is supported by previous 
studies $[4,13,29,35-37]$. Participants reflected slightly higher satisfaction with the winter performance of Green Star buildings. In winter, satisfaction scores were higher in Green Star buildings for air movement and humidity when compared with non-green buildings, while in summer, non-green buildings achieved a higher score for air odors when comparing Green Star with non-green buildings. This might be explained by the Australian subtropical climate holding more suitable conditions for natural ventilation in winter than in summer due to high humidity. Air freshness was also scored significantly lower in Green Star buildings than in conventional buildings. This could be explained by the lack of fresh air penetration through ventilation openings in the Green Star buildings.

Our study also confirmed lower satisfaction levels with noise in green-rated buildings, a finding which is in line with earlier studies [13,38,39]. Although noise interruption and noise from colleagues achieved no significant differences in green and non-green buildings, a more detailed analysis of noise satisfaction revealed that noise from other people and general inside noise resulted in higher satisfaction in Green Star than non-green buildings. In agreement with previous studies [40], the analysis of open comments confirmed that although participants in open-plan offices complained about noise interruptions, they favored the ease of interactions with colleagues.

Slightly higher satisfaction scores with natural lighting were reported in Green Star buildings. However, satisfaction with overall lighting showed no significant differences between green and non-green buildings. This finding contradicted with earlier studies which showed higher [39] and lower [10] perceived lighting satisfaction in green buildings. Surprisingly, artificial lighting and glare from artificial lighting attained a lower score in Green Star buildings, yet the effect size was very small (0.22 and 0.20). Issues related to artificial lighting in green buildings were reported in previous research [41], where too little artificial lighting was perceived in green buildings. This might be explained by the fact that more attention is paid to the design of natural lighting in green buildings, and artificial lighting designs are overlooked by many green designers.

In response to Hypothesis 3, the study of the influence of environmental factors on satisfaction results showed that the perceived control of IEQ parameters strongly correlated with satisfaction scores in non-green buildings, while no significant correlations were detected between the two in green buildings. This might be explained by Kano's theory of customer satisfaction. In Kano's model of product quality attributes [42], three product types are identified in regard to customer satisfaction: (1) must-be; (2) one-dimensional; and (3) attractive. Must-be types are those that, if not completely fulfilled, result in customer dissatisfaction [43]. In one-dimensional qualities, customer satisfaction is proportional to the level of fulfilment [44]. Attractive qualities are those which, if present, result in higher satisfaction, but if not present do not result in dissatisfaction [43]. The finding in our research suggests that IEQ controls are a must-be quality in green buildings, and a one-dimensional quality in non-green buildings.

Ventilation type as an important environmental factor affects occupant satisfaction as the study showed that occupant satisfaction was inconsistent in AC and MM buildings when comparing green with non-green buildings. In AC buildings, green buildings generally showed higher satisfaction scores, particularly in parameters related to thermal comfort and IAQ. In MM buildings, satisfaction levels were comparable in green and non-green buildings except in air freshness. Ventilation and provision of fresh air was found to be the weakness in MM buildings, because air freshness scored lower in MM green buildings compared with in non-green buildings, suggesting a lack of appropriate air circulation and ventilation in MM Green Star buildings.

To investigate Hypothesis 4, which is about the influence of non-environmental factors on occupant satisfaction, the survey data was partitioned into groups based on gender, age, sitting next to a window, working history in buildings and in workstations, and office layout. In line with findings from previous research [3], gender did not significantly affect satisfaction scores in Green Star and non-green buildings. However, earlier research $[3,40,45]$ detected slightly higher satisfaction scores by male participants, a result which is not in line with our findings. In our study, female participants showed slightly higher satisfaction scores than male participants, yet the statistical difference was 
insignificant, a finding which has been confirmed by a previous study [39]. Results related to the influence of participant age on satisfaction scores reflected contradictory findings with previous studies [46], suggesting that age might affect satisfaction. A significantly higher satisfaction score was detected in Green Star buildings, in our study, among participants aged 30 or over, yet for participants under 30, no significant differences between green and non-green buildings were noticed. Earlier research has shown that occupant expectations and perceived thermal comfort can be shifted by comfortable thermal experiences [47]. It could be inferred that participant age or previous thermal comfort experiences affect how green buildings are perceived in workplace environments, emphasizing psychological aspects.

In line with earlier research $[48,49]$, our study showed that the history of working in buildings and at workstations influences satisfaction scores by manifesting artificially higher satisfaction scores by participants who spent less than a year in their current buildings and at current workstations. This phenomenon is explained by a study by Singh and Syal [49], which suggested that perceived satisfaction levels are higher immediately after moving into a green building (also known as the "honeymoon" effect).

Results related to the consideration of office sharing on occupant satisfaction revealed an agreement with earlier studies [3] that the number of people using the office would affect occupant experiences and satisfaction. In our study, no significant differences were detected between green and non-green buildings in offices used only by one individual, while in offices used by more than 9 people, significantly higher satisfaction scores were reflected in Green Star buildings. However, the sample of office sharing types in the study was not consistent or evenly distributed. Future studies are recommended to create more consistent sample sizes regarding all office sharing types.

The studied Green Star buildings seemed to be more successful in meeting user needs and achieving higher satisfaction with BD\&FM parameters such as overall building comfort, building design, needs, building image, cleaning, the availability of meeting rooms, storage, and occupant health and productivity. Some of the design strategies common in the five Green Star buildings could be the central atrium and open-plan offices, the use of plants and vegetation in the interior design of buildings, and the utilization of biophilic design such as the use of natural ventilation and maximizing natural lighting in buildings. However, the same strategies resulted in some weaknesses in the performance of Green Star buildings, such as noise, air freshness, air odors, and artificial lighting. Particularly, open-plan office design resulted in higher satisfaction in parameters such as building design and building image but also resulted in lower satisfaction in noise parameters. Some weaknesses of Green Star rating systems could be related to noise and air quality. Improvements in rating buildings related to noise and air quality in the Green Star Design guide could help the improvement of building performance.

This paper focused only on subjective evaluations and user perspectives on green building performance. The objective evaluation of building performance and its correlation with green building certifications was not performed here; this is recommended for future studies. Another limitation of the paper is that the operational factors of the studied buildings, such as occupancy hours, ventilation operations, and facility management, were not correlated with building performance factors. However, it should be considered that the studied buildings were consistent in terms of operational factors because all the buildings were higher education buildings under the same management systems.

\section{Conclusions}

This research compared Green Star buildings with their non-green counterparts by evaluating occupant satisfaction and perceived indoor environmental conditions in office workplace environments. The study showed that Green Star buildings were generally more satisfactory when compared with non-green buildings, particularly in BD\&FM parameters such as overall building comfort, building design, needs, building image, cleaning, the availability of meeting rooms, storage, and 
occupant health and productivity. However, some weaknesses were detected, particularly in regard to IEQ parameters such as noise, air freshness, air odors, and artificial lighting.

Noise interruptions were particularly higher in open-plan offices; however, occupants in open-plan spaces favored the ease of interactions with colleagues. This suggests that innovative acoustic design and noise control in open-plan spaces are needed to enhance the acoustic performance of Green Star buildings. Low satisfaction scores with air freshness and air odors in summer could be explained by the efficiency of natural ventilation and the lack of air circulation in Green Star buildings. A study of fluid dynamics and air circulation in buildings at the design stage and green certification process seems appropriate to enhance the quality of air in Green Star buildings. Our study indicated that issues related to artificial lighting in green buildings have been generally overlooked in the past, as most green buildings put greater emphasis on natural lighting design.

Our research also identified indoor environmental controls as a must-be quality in green buildings, and as a one-dimensional quality in non-green buildings based on the definitions of Kano's theory. This suggests that the availability of indoor environmental control positively correlates with the level of perceived satisfaction in non-green buildings, but it does not necessarily increase perceived satisfaction in green buildings. However, the absence of indoor environmental controls would result in perceived dissatisfaction in green buildings.

The study of occupant satisfaction is recommended to consider participant background information regarding gender, age, sitting next to a window, the history of work in buildings and in workstations, and office layout, because our research has indicated that these non-environmental factors affect satisfaction in buildings.

Author Contributions: M.K. and Z.G. conceived, designed, and performed the experiments. M.K., Z.G. and X.X. drafted the paper. B.H. and A.D. reviewed the research and provided useful comments.

Funding: This research was funded by Research Start-up Funding for Newly Introduced Teacher of Shenzhen University grant number [2017043].

Acknowledgments: Funding for this research in Australia is provided by Griffith University as part of a $\mathrm{PhD}$ research program. Research Start-up Funding for Newly Introduced Teacher of Shenzhen University (No. 2017043) also supports the research. The authors are heartily thankful to Adrian Leaman for his support and provision of materials for the BUS surveys. They would also like to thank all participants and institute managers for their cooperation on the questionnaire survey. The Ethics Committee of Griffith University approved the survey. Subjects gave their consent to participate in the study.

Conflicts of Interest: The authors declare no conflict of interest. The founding sponsors had no role in the design of the study; in the collection, analyses, or interpretation of data; in the writing of the manuscript, and in the decision to publish the results.

\section{References}

1. U.S. Energy Information Administration. CBECS Survey Data. 2003. Available online: https://www.eia. gov/consumption/commercial/data/2003/ (accessed on 13 September 2017).

2. Roderick, Y.; McEwan, D.; Wheatley, C.; Alonso, C. Comparison of energy performance assessment between LEED, BREEAM and Green Star. In Proceedings of the Eleventh International IBPSA Conference, Glasgow, Scotland, 27-30 July 2009; pp. 27-30.

3. Altomonte, S.; Saadouni, S.; Schiavon, S. Occupant satisfaction in LEED and BREEAM-certified office buildings. In Proceedings of the PLEA 2016-36th International Conference on Passive and Low Energy Architecture: Cities, Buildings, People: Towards Regenerative Environments, Los Angeles, CA, USA, 11-13 July 2016.

4. Thatcher, A.; Milner, K. Is a green building really better for building occupants? A longitudinal evaluation. Build. Environ. 2016, 108, 194-206. [CrossRef]

5. Altomonte, S.; Schiavon, S. Occupant satisfaction in LEED and non-LEED certified buildings. Build. Environ. 2013, 68, 66-76. [CrossRef]

6. Geng, Y.; Ji, W.; Lin, B.; Zhu, Y. The impact of thermal environment on occupant IEQ perception and productivity. Build. Environ. 2017, 121, 158-167. [CrossRef] 
7. Liu, Y.; Wang, Z.; Lin, B.; Hong, J.; Zhu, Y. Occupant satisfaction in Three-Star-certified office buildings based on comparative study using LEED and BREEAM. Build. Environ. 2018, 132, 1-10. [CrossRef]

8. Dave, M.; Gou, Z.; Prasad, D.; Li, F. Greening Universities Toolkit V2. 0: Transforming Universities into Green and Sustainable Campuses: A Toolkit for Implementers-Advance Copy; United Nations Environment Programme: Washington, DC, USA, 2014.

9. Abbaszadeh, S.; Zagreus, L.; Lehrer, D.; Huizenga, C. Occupant satisfaction with indoor environmental quality in green buildings. In Proceedings of the HB 2006-Healthy Buildings: Creating a Healthy Indoor Environment for People, Lisboa, Portugal, 4-8 June 2006; pp. 365-370.

10. Lee, Y.S.; Kim, S.-K. Indoor environmental quality in LEED-certified buildings in the US. J. Asian Arch. Build. Eng. 2008, 7, 293-300. [CrossRef]

11. Huizenga, C.; Zagreus, L.; Abbaszadeh, S.; Lehrer, D.; Goins, J.; Hoe, L.; Arens, E. LEED post-occupancy evaluation: Taking responsibility for the occupants. In Proceedings of the GreenBuild, Atlanta, GA, USA, 9-11 November 2005.

12. Issa, M.H.; Rankin, J.H.; Attalla, M.; Christian, A.J. Absenteeism, Performance and Occupant Satisfaction with the Indoor Environment of Green Toronto Schools. Indoor Built Environ. 2011, 20, 511-523. [CrossRef]

13. Kim, S.K.; Hwang, Y.; Lee, Y.S.; Corser, W. Occupant comfort and satisfaction in green healthcare environments: A survey study focusing on healthcare staff. J. Sustain. Dev. 2015, 8, 156-173. [CrossRef]

14. Brown, Z.; Cole, R.J.; Robinson, J.; Dowlatabadi, H. Evaluating user experience in green buildings in relation to workplace culture and context. Facilities 2010, 28, 225-238. [CrossRef]

15. Newsham, G.R.; Birt, B.J.; Arsenault, C.; Thompson, A.J.L.; Veitch, J.A.; Mancini, S.; Galasiu, A.D.; Gover, B.N.; Macdonald, I.A.; Burns, G.J. Do 'green' buildings have better indoor environments? New evidence. Build. Res. Inf. 2013, 41, 415-434. [CrossRef]

16. Baird, G.; Leaman, A.; Thompson, J. A comparison of the performance of sustainable buildings with conventional buildings from the point of view of the users. Arch. Sci. Rev. 2012, 55, 135-144. [CrossRef]

17. Zhang, Y.; Altan, H. A comparison of the occupant comfort in a conventional high-rise office block and a contemporary environmentally-concerned building. Build. Environ. 2011, 46, 535-545. [CrossRef]

18. Leaman, A.; Bordass, B. Are users more tolerant of 'green' buildings? Build. Res. Inf. 2007, 35, 662-673. [CrossRef]

19. Paul, W.L.; Taylor, P.A. A comparison of occupant comfort and satisfaction between a green building and a conventional building. Build. Environ. 2008, 43, 1858-1870. [CrossRef]

20. Menadue, V.; Soebarto, V.; Williamson, T. Perceived and actual thermal conditions: Case studies of green-rated and conventional office buildings in the City of Adelaide. Arch. Sci. Rev. 2014, 57, 303-319. [CrossRef]

21. Leaman, A.; Thomas, L.; Vandenberg, M. 'Green' buildings: What Australian users are saying. EcoLibrium 2007, 6, 22-30.

22. Cary, G.; Lindenmayer, D.; Dovers, S. Australia Burning: Fire Ecology, Policy and Management Issues; Csiro Publishing: Victoria, Australia, 2003.

23. Australian Government. Climate Statistics for Australian Locations. 2017. Available online: http:/ / www. bom.gov.au/climate/averages/tables/cw_040764.shtml (accessed on 1 July 2017).

24. Cohen, R.; Standeven, M.; Bordass, B.; Leaman, A. Assessing building performance in use 1: The Probe process. Build. Res. Inf. 2001, 29, 85-102. [CrossRef]

25. Brown, Z.B.; Dowlatabadi, H.; Cole, R.J. Feedback and adaptive behaviour in green buildings. Intell. Build. Int. 2009, 1, 296-315. [CrossRef]

26. Gou, Z.; Lau, S.S.-Y.; Chen, F. Subjective and objective evaluation of the thermal environment in a three-star green office building in China. Indoor Built Environ. 2012, 21, 412-422. [CrossRef]

27. Leaman, A.; Bordass, B. Assessing building performance in use 4: The Probe occupant surveys and their implications. Build. Res. Inf. 2001, 29, 129-143. [CrossRef]

28. Baird, G.; Thompson, J. An examination of the distribution of user perception scores in a world-wide set of sustainable buildings. In Proceedings of the 44th Annual Conference of the Architectural Science Association (ANZAScA) University of Sydney, Sydney, Australia, 14-16 November 2011.

29. Lin, B.; Liu, Y.; Wang, Z.; Pei, Z.; Davies, M. Measured energy use and indoor environment quality in green office buildings in China. Energy Build. 2016, 129, 9-18. [CrossRef] 
30. Ferguson, C.J. An effect size primer: A guide for clinicians and researchers. Prof. Psychol. Res. Pract. 2009, 40, 532-538. [CrossRef]

31. Cohen, J. Statistical power analysis. Curr. Dir. Psychol. Sci. 1992, 1, 98-101. [CrossRef]

32. Bland, J.M.; Altman, D.G. Multiple significance tests: The Bonferroni method. BMJ 1995, 310, 170. [CrossRef] [PubMed]

33. Luo, M.; Cao, B.; Ji, W.; Qin, O.; Lin, B.; Zhu, Y. The underlying linkage between personal control and thermal comfort: Psychological or physical effects? Energy Build. 2016, 111, 56-63. [CrossRef]

34. Gou, Z.; Lau, S.S.-Y.; Zhang, Z. A comparison of indoor environmental satisfaction between two green buildings and a conventional building in China. J. Green Build. 2012, 7, 89-104. [CrossRef]

35. Azizi, N.S.M.; Wilkinson, S.; Fassman, E. An analysis of occupants response to thermal discomfort in green and conventional buildings in New Zealand. Energy Build. 2015, 104, 191-198. [CrossRef]

36. Gou, Z.; Lau, S.S.-Y.; Shen, J. Indoor Environmental Satisfaction in Two LEED Offices and its Implications in Green Interior Design. Indoor Built Environ. 2012, 21, 503-514. [CrossRef]

37. Ravindu, S.; Rameezdeen, R.; Zuo, J.; Zhou, Z.; Chandratilake, R. Indoor environment quality of green buildings: Case study of an LEED platinum certified factory in a warm humid tropical climate. Build. Environ. 2015, 84, 105-113. [CrossRef]

38. Goins, J.; Moezzi, M. Linking occupant complaints to building performance. Build. Res. Inf. 2013, 41, 361-372. [CrossRef]

39. Liang, H.-H.; Chen, C.-P.; Hwang, R.-L.; Shih, W.-M.; Lo, S.-C.; Liao, H.-Y. Satisfaction of occupants toward indoor environment quality of certified green office buildings in Taiwan. Build. Environ. 2014, 72, $232-242$. [CrossRef]

40. Kim, J.; de Dear, R. Workspace satisfaction: The privacy-communication trade-off in open-plan offices. J. Environ. Psychol. 2013, 36, 18-26. [CrossRef]

41. Baird, G. Sustainable Buildings in Practice: What the Users Think; Routledge: London, UK, 2010.

42. Xu, Q.; Jiao, R.J.; Yang, X.; Helander, M.; Khali, H.M.; Opperud, A. An analytical Kano model for customer need analysis. Des. Stud. 2009, 30, 87-110. [CrossRef]

43. Matzler, K.; Hinterhuber, H.H.; Bailom, F.; Sauerwein, E. How to delight your customers. J. Prod. Brand Manag. 1996, 5, 6-18. [CrossRef]

44. Matzler, K.; Fuchs, M.; Schubert, A. Employee satisfaction: Does Kano's model apply? Total Qual. Manag. Bus. Excell. 2004, 15, 1179-1198. [CrossRef]

45. Frontczak, M.; Schiavon, S.; Goins, J.; Arens, E.; Zhang, H.; Wargocki, P. Quantitative relationships between occupant satisfaction and satisfaction aspects of indoor environmental quality and building design. Indoor Air 2012, 22, 119-131. [CrossRef] [PubMed]

46. Frontczak, M.; Wargocki, P. Literature survey on how different factors influence human comfort in indoor environments. Build. Environ. 2011, 46, 922-937. [CrossRef]

47. Luo, M.; de Dear, R.; Ji, W.; Bin, C.; Lin, B.; Qin, O.; Zhu, Y. The dynamics of thermal comfort expectations: The problem, challenge and impication. Build. Environ. 2016, 95, 322-329. [CrossRef]

48. Schiavon, S.; Altomonte, S. Influence of factors unrelated to environmental quality on occupant satisfaction in LEED and non-LEED certified buildings. Build. Environ. 2014, 77, 148-159. [CrossRef]

49. Singh, A.; Syal, M.; Grady, S.C.; Korkmaz, S. Effects of Green Buildings on Employee Health and Productivity. Am. J. Public Health 2010, 100, 1665-1668. [CrossRef] [PubMed]

(C) 2018 by the authors. Licensee MDPI, Basel, Switzerland. This article is an open access article distributed under the terms and conditions of the Creative Commons Attribution (CC BY) license (http:/ / creativecommons.org/licenses/by/4.0/). 